\section{G. Wright, H. Betts, P. Murray}

Centre for Health Informatics Research and Development and University College Winchester Hampshire, England

\title{
Research and Education
}

\section{Health Informatics Masters Education, Online Learning and Student Support}

\section{Introduction}

This paper seeks to illuminate the design and development of a Master's programme in health informatics centred on the strategic, clinical and organisational dimensions of health informatics rather than the technology. The paper links the programme design to online educational research and pedagogy and seeks to substantiate its structure from this perspective. Finally it briefly outlines some of the issues pertinent to online programmes where several universities collaborate to facilitate learning across different countries.

\section{The Origins of the Programme}

The development of the MSc in Health Informatics at University College Winchester (UCW) is part of the strategic vision of the College. The Centre for Health Informatics Research and Development (CHIRAD) is a not-for-profit organisation that houses a virtual research community for health informatics. There are strong academic links between CHIRAD and the Health and Social Care subject group in the School of Social Sciences at the College.
CHIRAD is probably the first virtual Research and Development (R\&D) centre for health informatics. Its aim is to provide an environment for the development of health informatics as an academic subject. CHIRAD directors, Prof Graham Wright who works part-time at University College Winchester and Dr Helen Betts, who is the Head of Social Sciences, lead a team of 23 members who either hold academic posts in other institutions or have visiting research fellowships at University College Winchester. A primary objective for CHIRAD is providing a blend of academics and consultants to R\&D projects. Five of the CHIRAD team are members of the European Commission (EC) expert panel and have experience evaluating and reviewing EC projects. CHIRAD was the first UK academic institutional member of the International Medical Informatics Association (IMIA). CHIRAD has a formal Memorandum of Understanding with the Medical Research Council of South Africa with whom it is currently engaged in activities in South Africa, including collaborating with the University of Transkei in Umtata to develop a master's degree in health informatics. Similar links are being explored with Higher Education Institutions (HEI) in Cuba.
Members of CHIRAD, funded by the British Computer Society (BCS) Health Informatics Committee (HIC), have been hosting action research groups which have addressed the issues emanating from the implementation of the English National Programme for Information Technology (NPfIT). Another major research project, in conjunction with the University of Plymouth, was commissioned by the NHS Service Development Organisation (SDO) to identify the research questions which need to be addressed (and funded) in e-health over the next ten years.

The master's level programme was developed by a group of CHIRAD members based on their experiences of running similar programmes in health informatics at Manchester University, University of Surrey and Erasmus University and from involvement in International and National health informatics via the BCS, IMIA and the European Federation for Medical Informatics (EFMI). In designing the programme the IMIA recommendations for curricula were considered together with the skills and research interests of the teaching team. 


\section{Philosophy and rationale for the programme development}

David B. Shires from Canada, IMIA President 1980-1983, described health informatics as being

"The study of the nature and principles of information and its applications within all aspects of health care delivery". [1]

Health informatics can be seen to be concerned with the individual and group behaviour of health care personnel in their interaction with information and information technologies. Domains of health informatics include delivery of care and promotion of health, information management and technology and organisational settings of health care. In their ground breaking work on organisational issues, Aarts, Peel and Wright show how these three domains interact and contribute to the underpinning philosophy of the programme. [2]

In health care provision in the UK, fundamental changes are taking place in the practice of clinical work and in health care systems. Increased accountability, the demand for consistently high quality services, continuous improvements in health outcomes, cost containment and cost effectiveness are the main drivers for change. Information and communication technology is considered essential to enable the changes that support high quality clinical work and enhance the cost effectiveness of the health care system. Health care needs leaders who are able to anticipate and manage strategic organisational change, incorporating appropriate information and communication technologies. They must be able to establish an effective 'fit' between the needs of clinical work, the health care system and information and communication technologies. The master's programme is designed to address these issues.

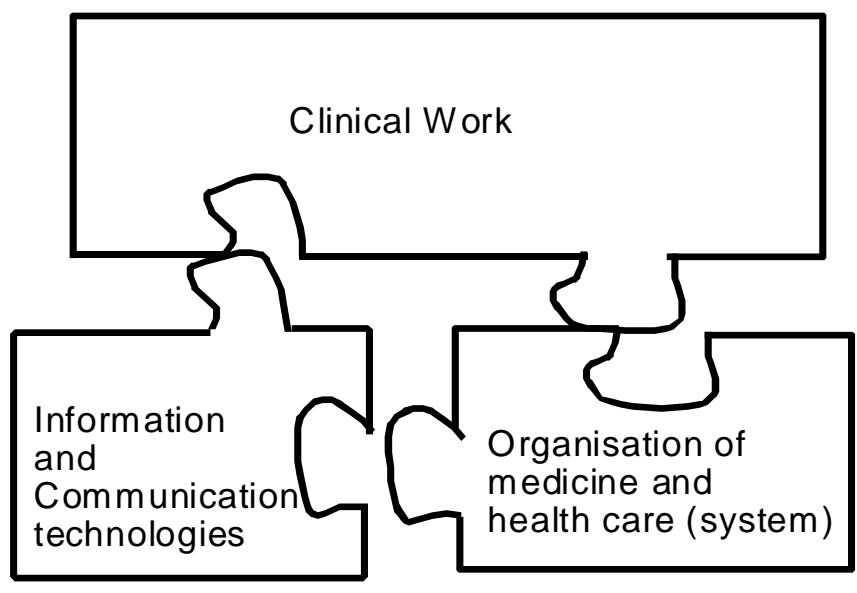

Three Domains Needing an "Effective Fit"

Fig. 1. Three Domains Needing an "Effective Fit".

Clinical work by its very nature is information dependent. However, the richness and complexity of clinical information is difficult to capture in computer-based information systems. Often the care process involves numbers of clinicians (doctors, nurses, and other health therapists) working in various organisational settings. The impact of information technology on clinical work has not been as beneficial as was expected by the developers, suppliers and purchasers of these technologies. Similarly, the expectation of benefits for the wider health care systems that are at local, regional and national levels, of improved quality of care, cost effectiveness and cost containment through information technology have generally not been met.

Increasingly technologies will only be valuable if the imperatives, the processes and requirements are sufficiently understood. The management of such changes is in itself a highly sophisticated skill. Identifying information requirements, choosing, procuring and implementing such rapidly developing technologies have a social as well as a technical dimension. It is only relatively recently that the extent of this social and individual dimension has been recognised as critical to the successful implementation of health and medical systems and the realisation of their benefits [3].

Individuals who have completed the Master's programme will be well qualified to create strategies and identify and manage complex projects that focus on facilitating changes in clinical and managerial work through the use of information technology. The programme brings together these subject domains to offer a unique understanding of health informatics. It is an academic programme giving strategic and clinical insights into the use of informatics, not a technician's course, although a module is included which addresses technical issues.

Table 1 shows the structure of the programme with each level designed to be a year of part time study. Each module is worth 20 credits and a student needs 60 credits for a postgraduate certificate, 120 credits for a post graduate diploma and 180 credits for a Master's degree. Each taught module follows a similar pattern of delivery over a sixteen week period; there is a pre-reading section, a taught study 
Table 1. The Structure of the Programme.

\begin{tabular}{|l|l|}
\hline & Post Graduate Certificate level \\
\hline Module 1 & Research Methods \\
\hline Module 2 & Health Informatics in Clinical Practice \\
\hline Module 3 & Clinical Measurement and Evidenced Based Medicine \\
\hline Module 4 & Post Graduate Diploma level \\
\hline Module 5 & Strategic Development \\
\hline Module 6 & Human and Organisational Issues in Informatics \\
\hline & Masters level \\
\hline Modules 7-9 & Masters Research Thesis \\
\hline
\end{tabular}

section (either block or day release) and a consolidation and assessment section supported by a virtual learning environment (VLE) and two web sites [4]. Students are expected to learn for at least 200 hours a module.

The philosophy of the MSc in Health Informatics is based on the College's general philosophy of graduate studies at master's degree level:

“...all masters' work must involve a productive dialectic and from this individual research directions must arise." [5]

The MSc in Health Informatics seeks to fulfil this general philosophy by developing the students' research, analytical and organisational skills through their work on an independent research project, the findings of which will be presented in the form of a dissertation. Graduate study is qualitatively different from undergraduate study, offering greater opportunity for more sophisticated modes of analysis, research, in-depth study and reflection.
Study is through a combination of lectures, seminars and group or personal tutorials with supporting materials available through the VLE. Stress is laid on active participation, staff-student interaction and student-led discussion. Students are asked to make short presentations and gain feedback and comments. In addition students are encouraged to use the VLE discussion list to debate selected issues and use email to keep in touch with their tutors. The College's VLE has been developed in-house and has similar functionality to Blackboard. Each academic group has an area which has the usual discussion facilities and module specific resource folders. The students also have rights to upload information into a project area. This has been successfully used for activities such as posting their literature critiques and PowerPoint presentations for their student-led seminars. There are also formal presentations by the teaching staff and external speakers. Students are expected to form learning sets in which practical exercises can take place.

\section{Online Pedagogy}

Mason [6], as a result of many years of work developing distance education and online courses, has described three models with varying degrees of usage of technology:

- Content and Support Model

- Wrap-around Model

- Integrated Model

In practice, implementation of student discussion activities requires course designers to structure the online environment, devising stimulating individual and groupactivities, providing small group discussion areas and supporting students through facilitative rather than instructive moderating [7]. A Higher Education Funding Council for England (HEFCE) consultation on e-learning called for a strategy that emphasized blended learning where elearning is augmented by other more traditional teaching methods including face to face contact in classrooms and the use of books [8]. Involvement through structured tasks, support, including periodic face to face contact, online tutor supervision, peer support, and advice from experts are seen to be important components, while the extent to which learners have control of key learning activities, and the extent to which students are encouraged to exercise that control have been shown, from the existing research, to facilitate online learning [9].

One of the key questions that is asked about any form of computermediated educational technology is whether it makes any difference, in terms of better student outcomes or results, more effective learning processes, more efficient processes, or of better being able to meet student or teacher needs. However, these questions are rarely, if ever, asked of the many traditional and non-computerbased educational strategies that have been used and developed over the years, and so there is often little 
objective baseline data against which to compare the newer technologies. Such literature studies as exist that compare online with conventional delivery modes generally highlight a 'no significant difference' phenomenon, meaning that there are no significant differences in the impact on learning between different modes $[10,11]$. Russell, [11] has compared over 400 studies and concludes that this phenomenon is widespread, meaning that online delivery is at least as good as traditional, offline methods, i.e. is no worse than them. Some exceptions exist, with other researchers claiming significantly better learning or outcomes for online delivery (e.g. [12, 13]).

Educational technology researchers are coming to the view that each medium has its strengths and weaknesses, and that learning outcomes are related more to how a particular medium is used than to any intrinsic characteristics of the medium itself $[14,10]$. This view has influenced the course team's decisions on programme structure and delivery in respect of the degree of use of technology.

Online education has often been criticised for being driven by the technology, not by the learning need, or the pedagogy. One substantive overview of the field, on which more recent literature largely draws, is Paulsen's [15] definition of pedagogic techniques to accomplish learning objectives. He produces a framework of pedagogic techniques, which he divides into four main areas:

- One alone techniques - the use of online databases, journals, etc.

- One to one techniques - using learning contracts, apprentice/ internships, correspondence studies

- One to many techniques - using electures, symposiums

- Many to many - involving the use of debates, role play, case studies, discussion, project groups.
The team have thus taken a pedagogical rather than a technological approach to support students' learning on the master's programme, using all four paradigms with varying foci throughout the programme to enhance and support different aspects of learning.

\section{Programme Ownership and other issues}

Students' expectations are also different in various countries, and the style of teaching and learning differs not only between cultures but also between professions. In the UK there has been a steady increase in the number of qualified teachers working in the Higher Education with a move away from amateur teachers with predominately research interests [16]. The intention is to raise the standard of education in HEIs to enable more students to benefit from the experience as well as giving HE staff a career structure. A result of this has been an emphasis on using a wider variety of teaching and learning approaches to match students' learning and living styles. Increasingly students in the UK are in employment whilst studying and this has encouraged the development of alternative delivery modes such as e-learning. However students still also expect to be taught. This has influenced the design of the master's programme where students come together for lectures and active learning as well as independent study via the VLE, which they can fit around work and family commitments.

The experience of having three universities collaborate with a master's programme highlighted the issues of programme ownership, validation, copyright, student registration and financial returns, which are so interwoven that it is difficult to see how trans-global collaborations could succeed. The ownership of a University programme is a prime issue which in the UK is usually vested in the institution that validates the programme. Also the students who register with a UK university attract a fee from the government. If a number of Universities combine to provide a programme, it needs to be determined before the students enrol which University's award is given to the students on successful completion and therefore which University will have the students registered with them and receive credits, both financial and status. This then leads into the resources to which the students have access. The normal model of many students to one VLE needs to be extended to embrace the notion of multiple VLEs or a shared VLE across institutional boundaries; the ultimate example being a transglobal VLE or virtual university. Access to a VLE, in the main, is restricted to those students who have paid a fee for the rights to access at that University. This then becomes another barrier to collaborative e-learning ventures. IMIA WG 1 concurs with these views reporting that "participants opposed formal accreditation of courses, citing a host of difficulties" [17].

\section{Conclusion}

The Master's programme uses elearning technology as an educational tool rather than a subject-specific technique for health informatics. It is complementary to traditional masters teaching methods and together support the development of the enquiring mind in post graduate students and the pace of life in the twenty first century.

A list of publications is available at ht t p://www.chirad.org.uk/ rec_pubs.htm and current projects at http://www.chirad.org.uk/projects.htm and http://www.chirad.info the open source website run by CHIRAD. 


\section{References}

1. Shires D. Computer Technology in Health Sciences. Springfield III: Charles C Thomas; 1974.

2. Aarts J, Peel V, Wright G. Organizational Issues in Health Informatics: a Model Approach. Int J Med Inf 1998;52:235-42.

3. Lorenzi NM, Riley RT. Managing Change: An Overview. J Am Med Inform Assoc 2000;7:116-24.

4. O'Leary R. Virtual Learning Environments.

Oxford: Association for Learning Technology and LTSN Generic Centre; 2002. Available: http://www.bbk.ac.uk/tlt/ resources/VLE.pdf

5. King Alfred's College. Common Academic Regulations for Taught Programmes Master's Programmes. Winchester; 1998.

6. Mason R. Models of Online Courses. ALN Magazine [online] 1998;2(2). Available: http://www.aln.org/alnweb/magazine/ vol2_issue2/Masonfinal.htm

7. SalmonG.E-moderating: the key to teaching and learning on-line., London: Kogan Page; 2000.

8. Higher Education Funding Council for England. The Council Briefing of the Higher Education Funding Council for England.
Bristol; 2004.

9. Coomey M, Stephenson J. Online learning: it is all about dialogue, involvement, support and control - according to the research. In: Stephenson J, editor. Teaching and learning online: pedagogies for new technologies. London: Kogan Page; 2001.

10. Hutchings M. Computer mediated communication: impact on learning. In: Fallows S, Bhanot R. Educational development through information and communications technology. Birmingham: Kogan Page/SEDA; 2002.

11. Russell TL. The no significant difference phenomenon, North Carolina State University; $1999 . \quad \mathrm{http}: / /$ teleeducation.nb.ca/nosignificantdifference/

12. Harasim L. What are we learning about teaching and learning online: an analysis of the Virtual-U field trials. British Columbia: Telelearning Network of Centres of Excellence; 1999. http://www.telelearn.ca/ g_access/research_projects/news/ vufieldtrials.pdf

13. Martunnen M. Teaching argumentation skills in an electronic mail environment. Innovations in Education and Training International 1997;34(3):208-18.

14. Ehrmann S. Asking the right question: what does research tell us about technology and higher education? Change: the magazine of higher learning [online] $199527 \mathrm{Mar} / \mathrm{Apr}$. http://www.learner.org/edtech/rscheval/ rightquestion.html

15. Paulsen MF. The online report on pedagogical techniques for computermediated communication. Oslo, Norway; 1995. http://www.nettskolen.com/ forskning/19/cmcped.html

16. Dearing R. The National Committee of Inquiry into Higher Education: Higher Education in the Learning Society. London: HMSO; 1997.

17. IMIA Working Group 1 Minutes $5^{\text {th }}$ September 2001, London

Address of the authors:

Graham Wright*, Helen Betts, Peter Murray Centre for Health Informatics Research and Development

University College Winchester Hampshire SO22 4NR

Hampshire, England

E-mail:Graham.Wright@Winchester.ac.uk

*Corresponding author 